\title{
Turkish Version of the Jefferson Scale of Empathy Psychometric Properties
}

\author{
Nazan Bilgel M.D., Prof. \\ Alis Ozcakir M.D., Prof. \\ Uludag University, Faculty of Medicine, \\ Department of Family Medicine, Bursa/Turkey
}

doi: 10.19044/esj.2017.v13n20p101 URL:http://dx.doi.org/10.19044/esj.2017.v13n20p101

\begin{abstract}
Empathy is an important component of medical education and could be taught throughout the years of medical study. Empathy is a skill that allows establishing a communication by evaluating the views, experiences and worries of the patients' cognitively. Empathy can improve physicianpatient communication, increase patient satisfaction, establish greater patient compliance, decrease litigation, improve physician's job satisfaction and prevent physician's burnout. Therefore measurement of this skill is important. Jefferson Scale of Empathy is an instrument for this purpose and has been translated into 45 languages and used in more than 70 countries. The objective of this study was to evaluate the reliability and construct validity of the Jefferson Scale of Empathy Turkish version. The scale was administered to 600 medical students in one medical school. Cronbach's alpha coefficient of the Jefferson Scale of Empathy was 0.85 which means a good reliability. Competing models of the latent structure of the Jefferson Scale of Empathy were derived from theoretical and empirical sources and evaluated using confirmatory factor analysis. The best fitting model of the latent structure of the Jefferson Scale of Empathy consisted of three correlated factors corresponding to the "perspective taking”, "compassionate care" and "standing in patient's shoes" dimensions. The reliability coefficients of these dimensions were $0.84,0.73$ and 0.62 respectively. The Turkish version of the Jefferson Empathy Scale is a reliable and valid measure of the constructs it was intended to assess. This measure was found useful for evaluating empathy among medical students.
\end{abstract}

Keywords: Jefferson Scale of Empathy, Medical Students, Turkey 


\section{Introduction}

Empathy is important in physician/patient interactions. The core components of empathy could be taught and enhanced during the medical education (Hojat et al., 2009a; Hojat et al 2009b). According to the American Association of Medical Colleges empathy is an essential skill for medical professionalism and this skill must be acquired through medical education (AAMC, 1998).

Jefferson Scale of Empathy was developed by Jefferson Medical College (now Sidney Kimmel Medical College) of Thomas Jefferson University Center for Research in Medical Education and Health Care (Hojat et al. 2009a). There are several versions of the Jefferson Scale of Empathy. We used the student version of this scale in our study.

Jefferson Scale of Empathy Student Version (JSE-S) has 20 items scored on the 7 point Likert type scale. Ten of these items with positive factor structure and correlations are scored on "Strongly Disagree $=1 \ldots . .$. Strongly Agree=7" whereas other ten items with negative factor structure and correlations are scored reversely (e.g., Strongly Disagree=7, Strongly Agree=1). Exploratory factor analytic studies of the scale have often resulted in three factors: "perspective-taking", "compassionate care" and "standing (walking) in patient's shoes" (Hojat et al. 2009a; Hojat \& LaNoue 2014). The three factors have also been shown in studies with the translated versions of the scale (Roh et al. 2010; Paro et al. 2012; Wen et al. 2013; Khademalhosseini et al 2014; Leombruni et al. 2014; Mostafa et al. 2014).

The first factor of the scale is the "perspective taking" with a score range of 10-70 and items 2,4,5,9,10,13,15,16,17 and 20. The second factor of the scale is "compassionate care" with a score range of 8-56 and items 1 , $7,8,11,12,14,18$ and 19 . The third factor is "standing in patient's shoes" and this factor has a score range of 2-14 and two items (item 3 and 6). The total score range of the scale is 20-140 and higher scores mean higher levels of empathy.

The Jefferson Scale of Empathy has been translated into 45 languages and used in more than 70 countries (Hojat \& LaNoue, 2014). Almost all of the studies reported Cronbach's alpha coefficients of the scale ranging from 0.70 to 0.80 which is indicating a good reliability (Hojat \& LaNoue, 2014). JSE-S was translated into Turkish by Gonullu \& Oztuna (2012) and their validation studies confirmed the three factor structure of the Turkish translation of the Jefferson Empathy Scale.

\section{Methods}

Study participants were 600 medical students from one public medical school in Turkey. Approval for the study was given by the 
institutional review committee. The permission to use the Jefferson Scale of Empathy Turkish version was given by the Center for Research in Medical Education and Health Care Thomas Jefferson University Jefferson Medical College. Participation was voluntarily and written consent for study participation was collected from those who agreed to participate. Printed Jefferson Scale of Empathy (in Turkish) and a questionnaire to collect the demographic data (gender, age, and year in school) were distributed to the participants. All of the printed materials were filled out by the participants anonymously.

Internal reliability of the Jefferson Empathy Scale Turkish version was assessed by means of Cronbach's $\alpha$ scores and item-total score correlations. The factorial validity was examined by implementation of exploratory and confirmatory factor analysis and structural equation modelling (SEM). For exploratory factor analysis, a principal component analysis (varimax with Kaiser normalization) was performed to test the validity of the original subscales. Evaluation of model fit was done by using confirmatory factor analysis (CFA). To perform the CFA, AMOS 16.0 was used, and the model parameters were estimated by using maximum likelihood (Joreskog \& Sorbom, 2001). In this study, adequacy of the model was assessed by: (a) root mean square error of approximation (RMSEA), which should be below 0.05 for a good fit; (b) the absolute fit, $\chi 2 /$ df measure that $\chi 2$ minimum fit function test depends on sample size (Bollen, 1989; Hair, Anderson,Tahtam et al., 1998) was used and should be between 2 and 5 for a good fit; (c) Goodness-of-fit index (GFI), which shows the amount of variances and covariance explained by the model and should be greater than 0.90 for an adequate fit of the model; and (d) comparative fit index (CFI), which should also be greater than 0.90 for adequate fit.

\section{Results}

Cronbach's alpha coefficient of the Jefferson Scale of Empathy was 0.85 in general and $0.84,0.73$ and 0.62 for the three dimensions "perspective taking”, “compassionate care" and "standing in patient's shoes" respectively. These values are in acceptable range which indicates that the Turkish version of Jefferson Scale of Empathy was internally consistent for psychological measures. Item- total score correlations for the Turkish version of Jefferson Scale of Empathy are shown in Table 1. Except JSE item 18 all correlations were significant at the 0.01 level.

Table 1. Item total score correlations for the Turkish version of Jefferson Scale of Empathy

\begin{tabular}{cccc}
\hline Item & Item total score correlation & Item & Item- total score correlation \\
\hline JSE1 & 0.53 & JSE11 & 0.71 \\
JSE2 & 0.47 & JSE12 & 0.59 \\
JSE3 & 0.23 & JSE13 & 0.53
\end{tabular}




$\begin{array}{cccc}\text { JSE4 } & 0.58 & \text { JSE14 } & 0.62 \\ \text { JSE5 } & 0.40 & \text { JSE15 } & 0.59 \\ \text { JSE6 } & 0.15 & \text { JSE16 } & 0.71 \\ \text { JSE7 } & 0.57 & \text { JSE17 } & 0.64 \\ \text { JSE8 } & 0.51 & \text { JSE18 } & 0.07 \\ \text { JSE9 } & 0.58 & \text { JSE19 } & 0.48 \\ \text { JSE10 } & 0.62 & \text { JSE20 } & 0.65\end{array}$

Except JSE18 all correlations were significant at the 0.01 level

The Kaiser-Meyer-Olkin analysis showed an index of 0.89 and the result of Bartlett's test of sphericity was $3564.78(\mathrm{p}<0.001)$. These results indicated the appropriateness of principal component analysis. Principal component factor extraction with varimax rotation of data for 20 items of the Turkish version of JSE-S showed a 3 factor structure. Item 18 of the Jefferson Empathy Scale was excluded because of the low factor loading (< 0.40). The three factors explained $47.46 \%$ of the variance. Items and factor loadings are given in Table 2.

Table 2. Principal Component Factor Analysis of the JSE-S Turkish Version

\begin{tabular}{|c|c|c|c|}
\hline Items & $\begin{array}{c}\text { Perspective } \\
\text { taking (1) }\end{array}$ & $\begin{array}{l}\text { Compassionate } \\
\text { care (2) }\end{array}$ & $\begin{array}{l}\text { Standing } \\
\text { in } \\
\text { patient's } \\
\text { shoes (3) }\end{array}$ \\
\hline $\begin{array}{c}\text { Patients feel better when their physicians } \\
\text { understand their feelings (2) }\end{array}$ & 0.446 & & \\
\hline $\begin{array}{c}\text { Understanding body language is as important as } \\
\text { verbal communication in physician-patient } \\
\text { relationships (4) }\end{array}$ & 0.502 & & \\
\hline $\begin{array}{l}\text { A physician's sense of humor contributes to a } \\
\text { better clinical outcome (5) }\end{array}$ & 0.459 & & \\
\hline $\begin{array}{l}\text { Physicians should try to stand in their patients' } \\
\text { shoes when providing care to them (9) }\end{array}$ & 0.640 & & \\
\hline $\begin{array}{c}\text { Patients value a physician’s understanding of } \\
\text { their feelings which is therapeutic in its own } \\
\text { right (10) }\end{array}$ & 0.603 & & \\
\hline $\begin{array}{c}\text { Physicians should try to understand what is } \\
\text { going on in their patients' minds by paying } \\
\text { attention to their nonverbal cues and body } \\
\text { language (13) }\end{array}$ & 0.517 & & \\
\hline $\begin{array}{l}\text { Empathy is a therapeutic skill without which } \\
\text { the physician's success is limited (15) }\end{array}$ & 0.646 & & \\
\hline $\begin{array}{l}\text { Physicians' understanding of the emotional } \\
\text { status of their patients, as well as that of their } \\
\text { families, is one important component of the } \\
\text { physician-patient relationship (16) }\end{array}$ & 0.746 & & \\
\hline $\begin{array}{l}\text { Physicians should try to think like their patients } \\
\text { in order to render better care (17) }\end{array}$ & 0.777 & & \\
\hline $\begin{array}{l}\text { I believe that empathy is an important } \\
\text { therapeutic factor in medical treatment (20) }\end{array}$ & 0.716 & & \\
\hline
\end{tabular}




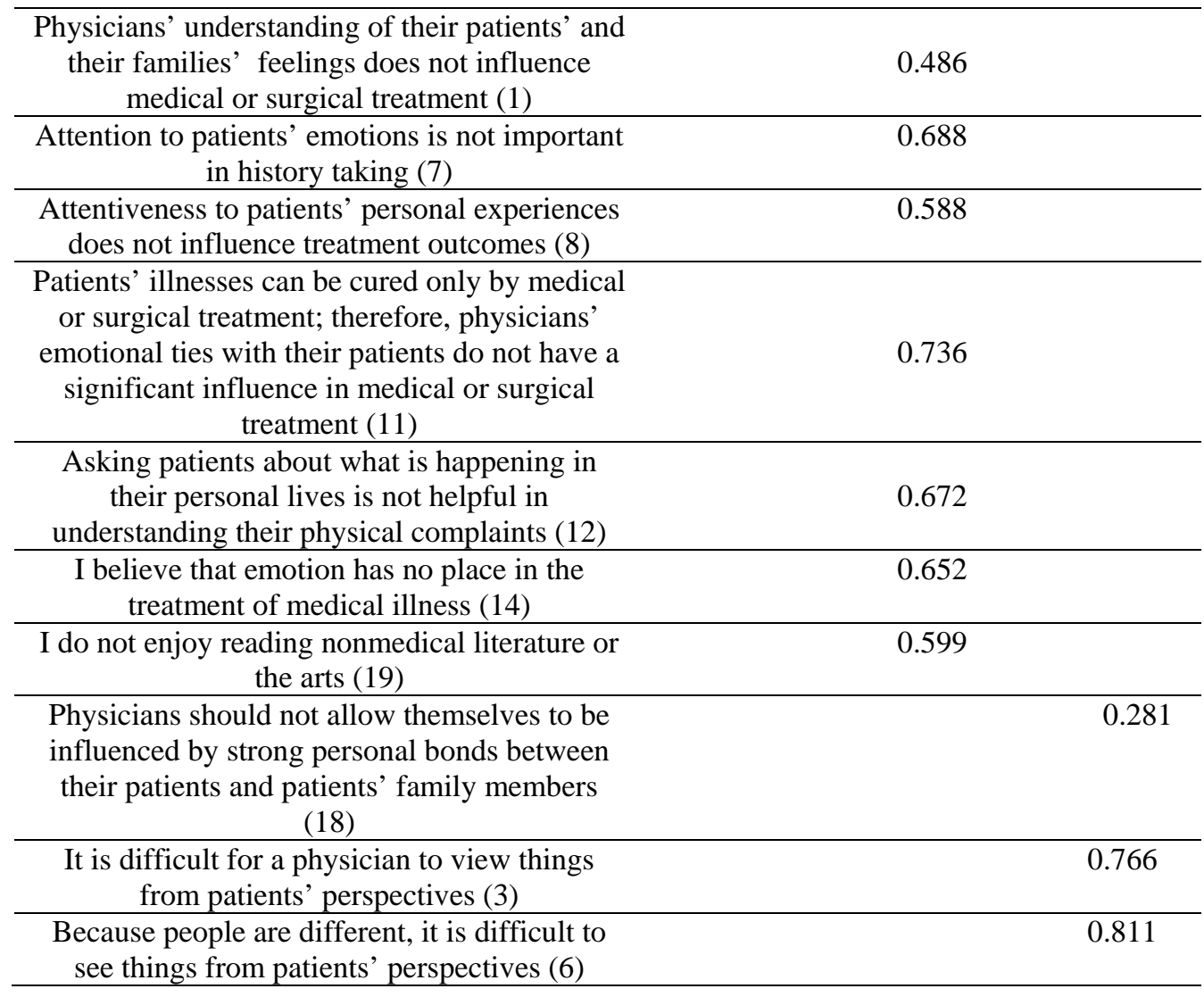

In order to test this three factor structure, confirmatory factor analysis was performed by Maximum Likelihood Estimation method. The fit indices of the model showed a good fit.

Table 3. Fit Indices of the Model

\begin{tabular}{cc}
\hline Fit indices & Value \\
\hline$\chi^{2}$ & 341.94 \\
$\mathrm{p}$ & $<0.001$ \\
$\mathrm{df}$ & 144 \\
$\chi^{2} / \mathrm{df}$ & 2.375 \\
(RMSEA) & 0.048 \\
Root Mean Square Error of Approximation & 0.040 \\
Standardized Root Mean Residual (SRMR) & 0.980 \\
Comparative Fit Index (CFI) & 0.960 \\
Normed Fit Index (NFI) & 0.940 \\
Goodness-of Fit Index (GFI) & 0.930 \\
\hline
\end{tabular}

The standardized solution and path coefficients of the model are shown in Figure 1 and the $\mathrm{t}$ values of the model in Figure 2. 


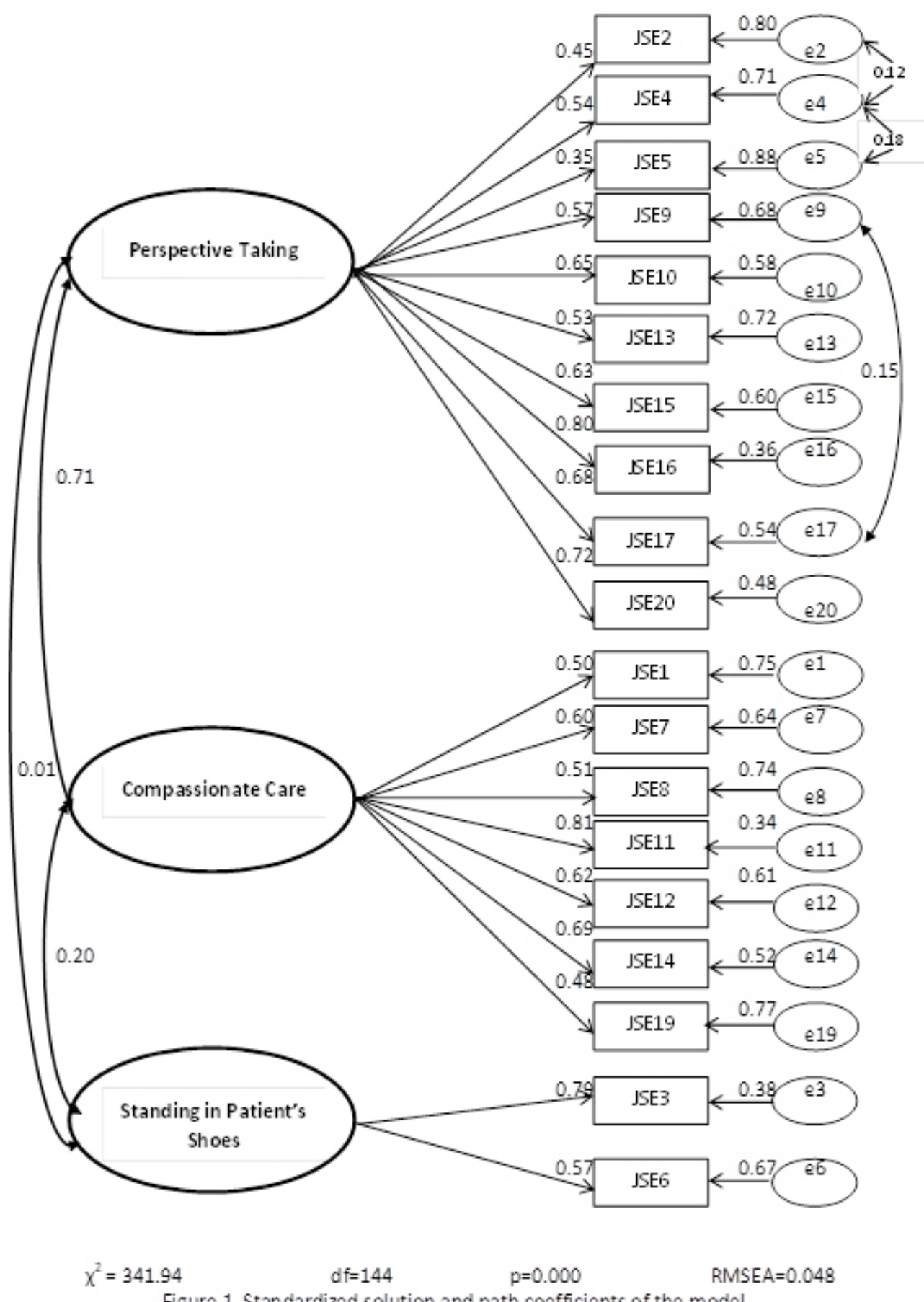

Figure 1. Standardized solution and path coefficients of the model 


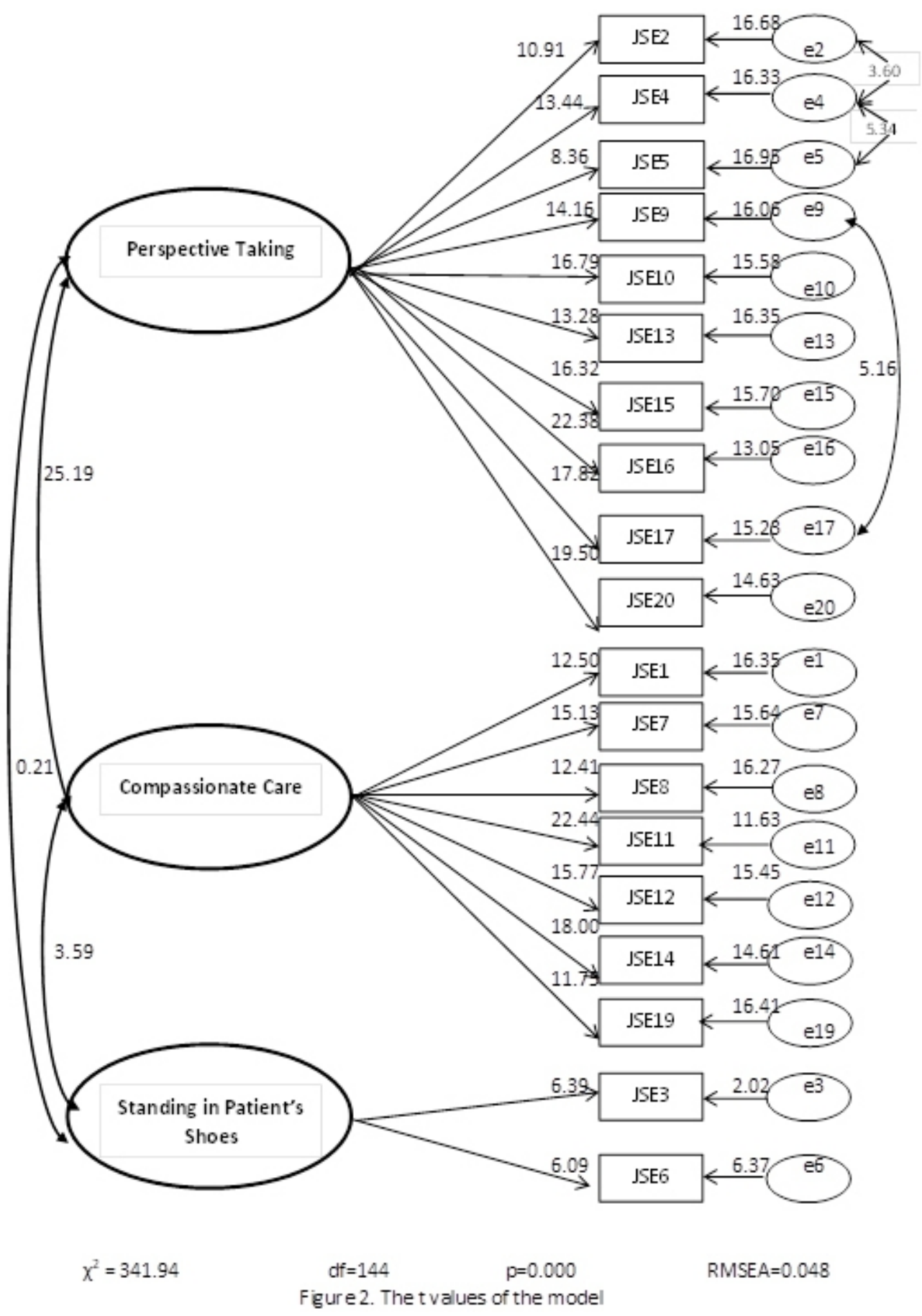


All items were positively and strongly correlated with their corresponding factors (perspective taking, compassionate care, and standing in patient's shoes) of the Jefferson Scale of Empathy. "Compassionate care" has strong and significant correlations with "perspective taking" ( $r=0.71$, tvalue $=25.19>1.96)$ and "standing in patient's shoes" $(r=0.20$, tvalue=3.59>1.96). Correlations between "perspective taking" and "standing in patient's shoes” were not significant.

\section{Conclusion}

In this study the reliability of the Turkish version of the Jefferson Scale of Empathy was found as 0.85 in general and 0.84, 0.73 and 0.62 for the three dimensions "perspective taking", "compassionate care" and "standing in patient's shoes" respectively. A previous study from Turkey found the internal consistencies in terms of the three dimensions of the scale as $0.83,0.70$ and 0.60 respectively (Gonullu \& Oztuna, 2012). Hojat \& LaNoue (2014) found the Cronbach's alpha coefficients for the corresponding three dimensions as $0.79,0.69$ and 0.68 and for the entire scale as 0.80 . Reliability coefficients of these magnitudes are considered acceptable by professional organizations (AERA, 1999).

Factor analytic studies of the original Jefferson Scale of Empathy have often resulted in the three factors. These factors are "perspective taking", "compassionate care" and "standing in patient's shoes" (Hojat \& LaNoue, 2014; Ward et al., 2009). However some studies with the original scale revealed two or four factors (Fjortoft et al. 2011; Sherman \& Cramer, 2005). Studies with the translated versions of the scale have mostly resulted in three factor structure as like as in this study. Some examples of these studies are: In Mexico with 1,022 medical students (Alcorta-Garza et al., 2005) ; in Japan with 400 medical students (Kataoka et al., 2009) ; in Korea with 493 medical students (Roh et al., 2010); in South Africa with 164 medical students (Vallabh, 2011), in Turkey with 752 medical students (Gonullu \& Oztuna, 2012) and in Spain with 1104 medical students (Ferreira-Valente et al., 2016) Both in this and in a previous study (Gonullu \& Oztuna, 2012) among Turkish medical students item 18 of the scale revealed a factor loading of $<0.40$ furthermore the item total score correlation found not statistically significant. Similar results for Item 18 were found in studies with Brazilian (Paro et al., 2012) Japanese (Kataoka et al., 2009) Chinese (Wen et al., 2013) and Italian (Leombruni et al., 2014) versions of the Jefferson Scale of Empathy. Item 18 of the Turkish version of the Jefferson Scale of Empathy should be re-arranged. The negative wording (...should not allow...) and the reverse scoring for this item could be the cause of the low factor loading and insignificant item total score correlation. Changing this item as: "Physicians should allow themselves to be influenced 
by strong personal bonds between their patients and their family members” with a scoring on 1=Strongly disagree to $7=$ Strongly agree may have yield different results. However this issue needs further assessment and evaluation including cultural variations.

There are only a few confirmatory factor analytic studies of the Jefferson Scale of Empathy. A study among 853 British medical students found the three factor model with a good fit (Tavakol et al., 2011). Another study on a sample of 1,187 Iranian medical students showed the three factor model with a moderate fit (Shariat \& Habibi, 2013).

Our study supported the previously reported findings on the reliability (Cronbach's $\alpha$ ), underlying constructs, and confirmation of the latent variable structure of the Jefferson Scale of Empathy. Similarities in factor pattern in different samples and countries indicate that the underlying components of the scale are relatively stable, regardless of cultural variation. In conclusion, this study has shown that the Jefferson Scale of Empathy can be used for measuring empathy among Turkish medical students with the exception of Item 18, "Physicians should not allow themselves to be influenced by strong personal bonds between their patients and their family members" in the original scale. The underlying reason for the unfitness of this item needs further evaluation.

\section{Acknowledgements}

This study was granted by the Scientific Projects Commission of Uludag University. Project number: HDP (T)-2014/37

\section{References:}

1. AAMC. (1998). Learning Objectives for Medical Student Education: Guidelines for Medical Schools. Medical School Objectives Projects.

2. AERA, APA, NCME. (1999). Standards for educational and psychological testing. Washington, DC: American Educational Research Association.

3. Alcorta-Garza, A., Gonzales-Guerrero, J.F., Tavitas-Herrera, S.E., Rodrigues-Lara, F.J., Hojat, M. (2005).Validation of the Jefferson Scale of Physician Empathy in Mexican medical students. Salud Mental. 28(5):57-63. Available at: http://www.medigraphic.com/pdfs/salmen/sam-2005/sam055h.pdf

4. Bollen, K.A.(1989). Structural equations with latent variables. New York: Wiley.

5. Ferreira-Valente, A., Costa, P., Elorduy, M., Virumbrales, M, Costa, M.J., Palés, J. (2016). Psychometric properties of the Spanish version of the Jefferson Scale of Empathy: making sense of the total score 
through a second order confirmatory factor analysis. BMC Medical Education, 16:242. DOI: 10.1186/s12909-016-0763-5

6. Fjortoft, N., Van Winkle, L.J., Hojat, M. (2011). Measuring empathy in pharmacy students. American Journal of Pharmaceutical Education, 75(6):109. DOI: 10.5688/ajpe756109

7. Gonullu, I., \& Oztuna, D. (2012). A Turkish Adaptation of the Student Version of the Jefferson Scale of Physician Empathy. Marmara Medical Journal, 25:87-92. DOI: 10.5472/MMJ.2012.02272.1

8. Hair, J.F., Anderson, R.E., Tahtam, R.L. (1998). Multivariate data analysis. New Jersey: Pearson Education.

9. Hojat, M., Gonnella, J.S., Maxwell, K.( 2009a). Jefferson Scales of Empathy (JSE). Professional Manual \& Users Guide. Philadelphia, PA: Jefferson Medical College Center for Research in Medical Education and Health Care.

10. Hojat, M., Vergare, M.J., Maxwell, K., Brainard, G., Herrine, S.K., Isenberg, G.A., et al. (2009b). The devil is in the third year: A longitudinal study of erosion of empathy in medical school. Academic Medicine, 84(9):1182-1191. DOI: 10.1097/ACM.0b013e3181b17e55

11. Hojat, M., \& LaNoue, M. (2014). Exploration and confirmation of the latent variable structure of the Jefferson scale of empathy. International Journal of Medical Education, 5:73-81. DOI: 10.5116/ijme.533f.0c41

12. Joreskog, K.G.,\& Sorbom, D.(2001). Lisrel 8: User's Reference Guide. Chicago: Scientific Software International.

13. Khademalhosseini, M., Khademalhosseini, Z., Mahmoodian, F. (2014). Comparison of empathy score among medical students in both basic and clinical levels. Journal of Advances in Medical Education \& Professionalism 2(2):88-91. Available at: https://www.ncbi.nlm.nih.gov/pmc/articles/PMC4235551

14. Kataoka, H., Koide, N., Ochi, K., Hojat, M., Gonnella, J.S.(2009). Measurement of empathy among Japanese medical students: psychometrics and score differences by gender and level of medical education. Academic Medicine, 84(9): 1192-1197. DOI: 10.1097/ACM.0b013e3181b180d4

15. Leombruni, P., Di Lillo, M., Miniotti, M., Picardi, A., Alessandri, G., Sica, C., et al.(2014). Measurement properties and confirmatory factor analysis of the Jefferson Scale of Empathy in Italian medical students.

16. Perspectives on Medical Education, 3(6):419-430. DOI: 10.1007/s40037-014-0137-9 
17. Mostafa, A., Hoque, R., Mostafa, M., Rana, M., Mostafa, F.(2014). Empathy in undergraduate medical students of Bangladesh: psychometric analysis and differences by gender, academic year, and specialty preferences. ISRN Psychiatry, 2014:375439. DOI: 10.1155/2014/375439

18. Paro, H.B.M.S., Daud-Gallotti,R.M., Tibério, I.C., Pinto, R.M.C., Martins, M.A.(2012). Brazilian version of the Jefferson Scale of Empathy: psychometric properties and factor analysis. BMC Medical Education, 12:73. DOI: 10.1186/1472-6920-12-73

19. Roh, M.S., Hahm, B.J., Lee, D.H., Suh, D.H.(2010). Evaluation of empathy among Korean medical students: a cross-sectional study using the Korean version of the Jefferson Scale of Physician Empathy. Teaching and Learning in Medicine, 22(3):167-171. DOI: 10.1080/10401334.2010.488191

20. Shariat, S.V., Habibi, M. (2013). Empathy in Iranian medical students: measurement model of the Jefferson Scale of Empathy. Medical Teacher 35:e913-e918. DOI: 10.3109/0142159X.2012.714881

21. Sherman, J.J.,\& Cramer, A. (2005). Measurement of changes in empathy during dental school. Journal of Dental Education, 69(3):338-345. Available at: http://www.jdentaled.org/content/69/3/338.full.pdf+html

22. Tavakol, S., Dennick, R., Tavakol, M. (2011) Psychometric properties and confirmatory factor analysis of the Jefferson Scale of Physician Empathy. BMC Medical Education, 11:54. DOI: 10.1186/1472-6920-11-54

23. Ward, J., Schaal, M., Sullivan, J., Bowen, M.E., Erdmann, J.B., Hojat, M. (2009). Reliability and validity of the Jefferson Scale of Empathy in undergraduate nursing students. Journal of Nursing Measurement, 17(1):73-88. DOI: 10.1891/1061-3749.17.1.73

24. Wen, D., Ma, X., Li, H., Liu, Z., Xian, B., Liu, Y. (2013). Empathy in Chinese medical students: psychometric characteristics and differences by gender and year of medical education. BMC Medical Education 13:130.

25. DOI: $10.1186 / 1472-6920-13-130$

26. Vallabh K.(2011). Psychometrics of the student version of the Jefferson Scale of Physician Empathy (JSPE-S) in final-year medical students in Johannesburg in 2008. South African Journal of Bioethics and Law, 4(2):63-68. DOI::10.7196/SAJBL.164. 